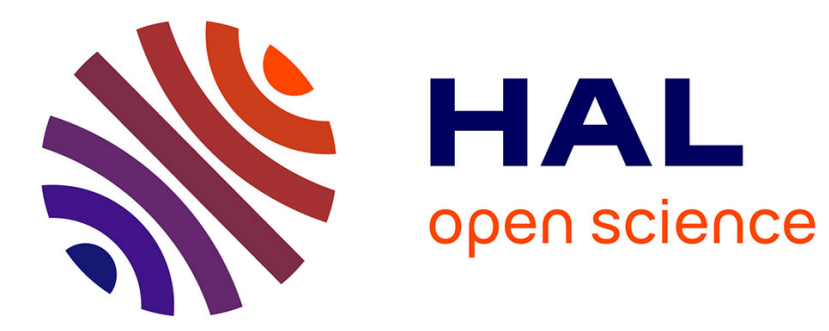

\title{
Radiolytic Method as a Novel Approach for the Synthesis of Nanostructured Conducting Polypyrrole
} Zhenpeng Cui, Cecilia Coletta, Alexandre Dazzi, Patrice Lefrancois, Matthieu Gervais, Stéphane Néron, Samy Remita

\section{- To cite this version:}

Zhenpeng Cui, Cecilia Coletta, Alexandre Dazzi, Patrice Lefrancois, Matthieu Gervais, et al.. Radiolytic Method as a Novel Approach for the Synthesis of Nanostructured Conducting Polypyrrole. Langmuir, 2014, 30, pp.14086-14094. 10.1021/la5037844 . hal-01088705

\section{HAL Id: hal-01088705 https://hal.science/hal-01088705}

Submitted on 12 Jan 2015

HAL is a multi-disciplinary open access archive for the deposit and dissemination of scientific research documents, whether they are published or not. The documents may come from teaching and research institutions in France or abroad, or from public or private research centers.
L'archive ouverte pluridisciplinaire HAL, est destinée au dépôt et à la diffusion de documents scientifiques de niveau recherche, publiés ou non, émanant des établissements d'enseignement et de recherche français ou étrangers, des laboratoires publics ou privés. 


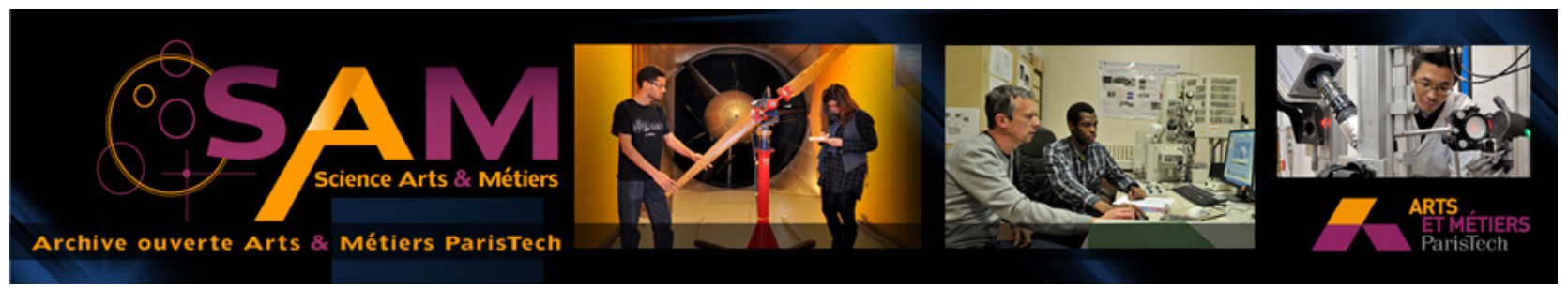

Science Arts \& Métiers (SAM)

is an open access repository that collects the work of Arts et Métiers ParisTech researchers and makes it freely available over the web where possible.

This is an author-deposited version published in: http://sam.ensam.eu

Handle ID: .http://hdl.handle.net/10985/9010

\section{To cite this version :}

Zhenpeng CUI, Cecilia COLETTA, Alexandre DAZZI, Patrice LEFRANCOIS, Matthieu GERVAIS, Stéphane NERON, Samy REMITA - Radiolytic Method as a Novel Approach for the Synthesis of Nanostructured Conducting Polypyrrole - Langmuir - Vol. 30, p.14086-14094 - 2014 


\title{
Radiolytic Method as a Novel Approach for the Synthesis of Nanostructured Conducting Polypyrrole
}

\section{Zhenpeng Cui, ${ }^{\dagger}$ Cecilia Coletta, ${ }^{\dagger}$ Alexandre Dazzi, ${ }^{\dagger}$ Patrice Lefrancois, ${ }^{*}$ Matthieu Gervais, ${ }^{\ddagger}$ Stéphane Néron ${ }^{\S}$ and Samy Remita* ${ }^{*} \dagger, \S$}

\footnotetext{
†Laboratoire de Chimie Physique, LCP, UMR 8000, CNRS, Université Paris-Sud, Bât. 349, Campus d’Orsay, 15 avenue Jean Perrin, 91405 Orsay Cedex, France

†Laboratoire Procédés et Ingénierie en Mécanique et Matériaux, PIMM/ENSAM, CNRS, CNAM, 151 boulevard de l'hôpital, 75013 Paris, France

${ }^{\S}$ Département CASER, Ecole SITI, Conservatoire National des Arts et Métiers, CNAM, 292 rue Saint-Martin, 75141 Paris Cedex 03, France
}

Key words: Radiolysis, Conducting polymers, Polypyrrole, Nanostructures, AFM-IR

\begin{abstract}
In this study, a novel and extremely facile method for the synthesis of conducting polypyrrole (PPy) was achieved in aqueous solution. This radiolytic method is totally free of template and environmentally friendly compared with traditional chemical methods. According to ultraviolet-visible (UV-vis) spectroscopy and Fourier transform infrared (FTIR) spectroscopy analysis, pyrrole (Py) monomers were polymerized into PPy thanks to their oxidation by HOradicals produced by the radiolysis of water when exposed to $\gamma$ irradiation. The morphology of PPy was characterized by Cryo-transmission electron microscopy (Cryo-TEM) in aqueous solution and by scanning electron microscopy (SEM) after deposition. In an original way, high resolution atomic force microscopy, coupled with infrared nanospectroscopy, is used to probe the local chemical composition of PPy nanostructures. The results demonstrated that spherical and chaplet-like PPy nanostructures were formed by $\gamma$-radiolysis. Thermogravimetric analysis (TGA) and electronic conductivity measurements showed that radiosynthesized PPy had good thermal stability and an electrical conductivity higher than that of chemically synthesized PPy.
\end{abstract}




\section{Introduction}

Conducting polymers (CPs), as a novel generation of polymers, ${ }^{1-3}$ have been intensively investigated due to their intrinsically unique $\pi$-conjugated systems which enable their potential applications in various fields such as conducting materials, ${ }^{4}$ photovoltaic cells, ${ }^{5}$ field effect transistors, ${ }^{6}$ chemical or biological sensors and anti-corrosion materials. ${ }^{7-9}$ Since their discovery, a variety of $\pi$-conjugated CPs have been developed and these typical CPs include poly(3,4ethylenedioxythiophene) (PEDOT), ${ }^{10}$ polypyrrole (PPy), ${ }^{11}$ polyaniline (PANI) and their derivatives. ${ }^{12}$ All these CPs are characterized to possess both environmental stability and high conductivity which are attracting great interests currently. ${ }^{13}$

Among these typical CPs, PPy has been mostly investigated due to its relatively easier synthesis and greater stability. Generally, the polymerization of pyrrole monomers, Py, into PPy (Scheme 1) could be achieved by traditional chemical (e.g., $\mathrm{K}_{2} \mathrm{~S}_{2} \mathrm{O}_{8}, \mathrm{FeCl}_{3}, \mathrm{H}_{2} \mathrm{O}_{2}$ ) and electrochemical methods while some alternative ways, such as enzymatic method, remain rarely proposed in literature. ${ }^{14-18}$ Although the polymerization technologies of chemical and electrochemical methods are quite different, the first step of polymerization corresponds to the preliminary oxidation of Py monomers into their ionic states which systematically preceeds and initiates the polymerization process. ${ }^{19,20}$

Although the synthesis of PPy polymers has been widely studied for a long time, many efforts are still being spent on simplifying their preparation and optimizing their properties. ${ }^{21,22}$ Compared with the common chemical and electrochemical methods, radiolytic method is based on the interaction of high energy ionizing radiations with matter. Instead of using external oxidative chemicals to initiate polymerization as in the case of chemical method, $\gamma$-radiolysis of aqueous solution leads to the quantitative and selective in situ production of radicals which come from the more abundant species present in the medium: the solvent molecules. These radicals, such as hydroxyl radicals $\left(\mathrm{HO}^{\bullet}\right)$ which are known to be very oxidative species should then act as initiators of PPy synthesis. ${ }^{23}$ In this way, the synthetic procedure is easier and environmentally friendly. In other words, water is used as the solvent without addition of chemical oxidants.

We recently, and for the first time in literature, succeeded in the synthesis of a $\mathrm{CP}$ in aqueous solution, namely poly(3,4-ethylenedioxythiophene), PEDOT, thanks to the use of different 
oxidizing species produced by water radiolysis. ${ }^{24}$ We showed that the polymerization growth of $\mathrm{CP}$ proceeds through a recurrent step-by step oxidation process. This means that for a quantitative polymerization the concentration of oxidizing species must be at least two times higher than that of monomers. Also, we demonstrated that the nature of the oxidizing species produced from water radiolysis determines the morphology as well as the physicochemical properties of the radiosynthesized PEDOT nanostructures. ${ }^{25}$

In this work, we extend our original radiolytic methodology to the synthesis of another CP, the polypyrrole (PPy) in aqueous solution under $\mathrm{N}_{2} \mathrm{O}$ atmosphere. Under these conditions, the hydroxyl radical $\left(\mathrm{HO}^{\bullet}\right)$ produced by water radiolysis should act as an oxidizing species towards Py monomers leading to PPy polymers. For comparison purpose, PPy polymers are also synthesized by traditional chemical method using $\mathrm{K}_{2} \mathrm{~S}_{2} \mathrm{O}_{8}$ as oxidant and as polymerization initiator. The morphology and the properties of PPy synthesized by both methods are compared in details.

\section{Experimental}

\subsection{Materials}

Pyrrole (Py) ( $\geq 98 \%$, Sigma Aldrich) was used as monomer and ultrapure water (Millipore system $18.2 \mathrm{M} \Omega \mathrm{cm}$ ) was used as the solvent. $\mathrm{K}_{2} \mathrm{~S}_{2} \mathrm{O}_{8}$ (Reagent grade, Touzart \& Magnon) was used as the oxidant during chemical polymerization. $\mathrm{N}_{2} \mathrm{O}$ (Air liquid Co.) was used to degas the aqueous solutions of pyrrole before $\gamma$ irradiation. Acetonitrile solvent ( $\geq 99.8 \%$, Sigma Aldrich), containing $\mathrm{NOBF}_{4}(\geq 95 \%$, Sigma Aldrich) as the dopant, was used during the electrical conductivity measurements.

\subsection{PPy synthesis methodologies}

\subsubsection{Radiolytic method}

Within the nanosecond timescale, $\gamma$-irradiation of deoxygenated diluted aqueous solutions at 
neutral $\mathrm{pH}$, generates the following radiolytic species which come from the direct effect of ionizing radiation on the more abundant species, namely water molecules: ${ }^{26-28}$

$\mathrm{H}_{2} \mathrm{O} \rightarrow \mathrm{n} \rightarrow \mathrm{HO} \cdot \mathrm{H}^{\bullet}, \mathrm{e}_{\mathrm{aq}}^{-}, \mathrm{H}_{2} \mathrm{O}_{2}, \mathrm{H}_{3} \mathrm{O}^{+}, \mathrm{H}_{2}$

While hydroxyl radical $\mathrm{HO} \bullet$ is a very oxidative species, hydrated electron $\mathrm{e}_{\mathrm{aq}}{ }^{-}$is a very reducing radical. In order to scavenge hydrated electrons, the aqueous solutions are degassed and saturated with nitrous oxide $\left(\mathrm{N}_{2} \mathrm{O}, 25 \mathrm{mM}\right)$. Under these conditions, $\mathrm{e}_{\mathrm{aq}}{ }^{-}$are quantitatively converted into hydroxyl radicals: ${ }^{26,27}$

$\mathrm{e}_{\mathrm{aq}}{ }^{-}+\mathrm{N}_{2} \mathrm{O}+\mathrm{H}_{2} \mathrm{O} \rightarrow \mathrm{HO}^{\bullet}+\mathrm{HO}^{-}+\mathrm{N}_{2}$

Therefore, upon irradiating $\mathrm{N}_{2} \mathrm{O}$-saturated aqueous solutions at neutral $\mathrm{pH}$, the radiolytic yield of formation of $\mathrm{HO} \bullet$ is well-known: ${ }^{25}$

$\mathrm{G}(\mathrm{HO} \cdot)=5.6 \times 10^{-7} \mathrm{~mol} \cdot \mathrm{J}^{-1}$

The concentration of hydroxyl radical [HO•] produced by water radiolysis can then be expressed as a function of the irradiation dose, D expressed in Gray (Gy, 1 Gy corresponds to $1 \mathrm{~J} \cdot \mathrm{kg}^{-1}$ or 1 $\mathrm{J} \cdot \mathrm{L}^{-1}$ for diluted solution) according to:

$[\mathrm{HO} \bullet]\left(\mathrm{mol} \cdot \mathrm{L}^{-1}\right)=\mathrm{D}(\mathrm{Gy}) \times \mathrm{G}(\mathrm{HO} \bullet)\left(\mathrm{mol} \cdot \mathrm{J}^{-1}\right)$

As demonstrated in our previous work, ${ }^{24,25}$ for quantitative polymerization of $\mathrm{CP}$, the concentration of oxidative species $\left(\mathrm{HO} \bullet\right.$ here) should be twice that of monomers (Py here), $[\mathrm{Py}]_{0}$. As a consequence, the dose $\mathrm{D}_{\max }$ needed for a quantitative polymerization can be calculated as follows:

$\mathrm{D}_{\max }(\mathrm{Gy})=\frac{2[\mathrm{Py}]_{0}\left(\mathrm{~mol} \cdot \mathrm{L}^{-1}\right)}{\mathrm{G}(\mathrm{HO} \cdot)\left(\mathrm{mol} \cdot \mathrm{J}^{-1}\right)}$

It thus amounts to $3.6 \mathrm{kGy}$ for $1 \mathrm{mM}$ in Py and to $72 \mathrm{kGy}$ for $20 \mathrm{mM}$ in Py. 
Aqueous solutions containing different concentrations in pyrrole ranging between 1 and 20 $\mathrm{mM}$ were prepared. Note that these concentrations are both by far lower than Py solubility in water $(0.9 \mathrm{M})$. These concentrations also remain very much lower than water molecules concentration $(55.5 \mathrm{M})$. This enables to neglect the direct effect of ionizing radiation on Py. Then, the samples were degassed with $\mathrm{N}_{2} \mathrm{O}$ for $20 \mathrm{~min}$ and irradiated with a ${ }^{60} \mathrm{Co} \gamma$ source (available at LCP laboratoire, Université Paris-Sud) at a dose rate of $6 \mathrm{kGy} \cdot \mathrm{h}^{-1}$ up to $\mathrm{D}_{\max }$.

\subsubsection{Chemical method}

For comparison purpose, PPy was also synthesized by a chemical method. Aqueous solution containing both pyrrole monomers $(20 \mathrm{mM})$ and $\mathrm{K}_{2} \mathrm{~S}_{2} \mathrm{O}_{8}$ oxidant $(40 \mathrm{mM})$ was prepared and stirred for another $24 \mathrm{~h}$ to ensure that Py monomers fully polymerized into polypyrrole. ${ }^{29}$ As in the case of radiolytical method, the molar ratio of monomer to oxidant was 1:2 to ensure quantitative polymerization.

\subsubsection{Lyophilization}

All the solutions of Py after polymerization were dried by lyophilization with a Heto PowerDry® LL1500 (Thermo Electron Co., France) to obtain dehydrated powders. The drying procedures were carried out as follows: first, all the solutions were transfered to culture dishes and frozen into ices; then, the frozen samples were moved to the drying chamber and lyophilized at $-110^{\circ} \mathrm{C}$ for $48 \mathrm{~h}$. After lyophilization, all the samples were further directly investigated by ATR-FTIR, SEM and TGA.

\subsection{Characterization of PPy}

\subsubsection{UV-vis absorption spectroscopy}

In order to check whether the polymerization of pyrrole monomers occurred, Ultravioletvisible (UV-vis) spectra of pyrrole aqueous solutions or suspensions before and after polymerization were recorded on a UV-vis scanning spectrophotometer (HP 8453) in quartz cell 
with an optical path length of $0.2 \mathrm{~cm}$. The reference was always ultrapure water.

\subsubsection{ATR-FTIR spectroscopy}

To further identify PPy and its chemical composition, the Fourier transform infrared (FTIR) spectra of lyophilized PPy were recorded using a FTIR spectrometer (Bruker Vertex 70) with diamond ATR attachment (PIKEMIRACLE crystal plate diamond/ZnSe) and MCT detector with a liquid nitrogen cooling system. The lyophilized powder was deposited onto the ZnSe diamond and scanning was conducted from 4000 to $600 \mathrm{~cm}^{-1}$ with a $4 \mathrm{~cm}^{-1}$ spectral resolution for 100 times and averaged for each spectrum.

\subsubsection{Cryo-transmission electron microscopy}

In order to observe the morphology of radiosynthesized PPy polymers in aqueous solutions, in-situ observation of the morphology of PPy was carried out on a transmission electron microscope in a cryogenic environment (Cryo-TEM), known to be adapted to low density contrasts. A drop of each solution was deposited on “quantifoil” ( (Quantifoil Micro Tools Gmbh, Germany) 200 mesh holey-carbon-coated grids. After being blotted with filter paper, the grids were quench-frozen by being rapidly plunged into liquid ethane in order to form a thin ice film avoiding water crystallization. The grids were then transferred into the microscope using a side entry Gatan 626 cryoholder cooled at $-180{ }^{\circ} \mathrm{C}$ with liquid nitrogen. Images were taken with an Ultrascan 2k CCD camera (Gatan, USA) by using a LaB6 JEOL JEM 2100 (JEOL, Japan). Advantages of Cryo-TEM are not only ensuring the observation of soft nanostructures but also avoiding the phase transition and aggregation which should result from the drying procedures.

\subsubsection{AFM-IR spectromicroscopy}

In order to check whether the radiosynthesized PPy maintained its original morphology during the drying process, after $\gamma$ irradiation, a small drop of the solution was deposited onto the upper surface of ZnSe prism (transparent in the mid-IR) and dried naturally at air. The dried deposit was observed by nanoIR ${ }^{\mathrm{TM}}$ (@Anasys Instruments) an AFM-IR system that combines the 
AFM with a pulsed infrared OPO laser to perform spectromicroscopy. AFM which has a visible laser focusing on the cantilever and a four quadrants detector measuring its deflection, was used for the superficial morphology characterization in contact mode. ${ }^{30-32}$ To obtain relevant infrared spectra, the pulsed infrared laser setup covers the wavenumbers from $3600 \mathrm{~cm}^{-1}$ to $1000 \mathrm{~cm}^{-1}$. During the measurement, the tip of the AFM remained in contact with the object. When the sample absorbs IR laser pulse, the absorbing region warms via the photothermal effect and a rapid thermal expansion occurs which then impacts the tip of the AFM cantilever and causes its oscillation. As the amplitude of oscillations is proportional to the absorption, scanning the surface with a given wavenumber enables the drawing of chemical map of the sample, while changing the wavelength on a fixed position of the tip gives a local infrared spectrum.

\subsubsection{SEM microscopy}

In order to check the morphology of PPy polymers synthesized by radiolytic and chemical methods, PPy powder obtained after lyophilization was sprinkled onto carbon tape adhered to aluminum mounts and the images were obtained with EVO MA10 scanning electron microscope (SEM). Magnification, accelerating voltage and scale bar were $5 \mathrm{~K} \mathrm{X}, 150 \mathrm{kV}$ and $1 \mu \mathrm{m}$.

\subsubsection{TGA analysis}

The thermal stability and composition analysis of lyophilized PPy was performed on a thermogravimetric analysis instrument TGA Q500 (TA instruments, USA) under a nitrogen flow of $50 \mathrm{~mL} / \mathrm{min}$. The temperature ranged from 40 to $800{ }^{\circ} \mathrm{C}$ at a heating rate of $20{ }^{0} \mathrm{C} / \mathrm{min}$.

\subsubsection{Conductivity test}

To measure the conductivity of PPy, spin-coated films of PPy were obtained by spinning a small drop of PPy suspensions on an ITO substrate. Before measurements, the nanostructures of PPy solutions or suspensions were doped with $\mathrm{NOBF}_{4}$ at a concentration of $10^{-2} \mathrm{M}$ in acetonitrile. A Kelvin four-point probe technique was used for measuring the resistance of PPy film and a 3 Veeco Dektak 150 surface profiler was used for the thickness measurement of the film. 
The conductivity, $\rho\left(\mathrm{S} \cdot \mathrm{cm}^{-1}\right)$ was determined thanks to the following equation:

$\rho=\left(\frac{\pi}{\ln 2} \times \frac{V}{I} \times t\right)^{-1}$

where $\mathrm{V}$ is the voltage difference $(\mathrm{V}), \mathrm{t}$ the film thickness $(\mathrm{cm})$ and $\mathrm{I}$ the applied current (A).

\section{Results and discussion}

\subsection{HO•-induced oxidation of Py monomers}

Aqueous solution containing $1 \mathrm{mM}$ in Py was prepared under $\mathrm{N}_{2} \mathrm{O}$ atmosphere. Its $\mathrm{UV}$-vis absorption spectrum presented in Figure 1 displays the $205 \mathrm{~nm}$ characteristic peak of Py monomers which corresponds to a $\pi-\pi^{*}$ transition. ${ }^{33}$ The molar extinction coefficient amounts to: $\varepsilon_{205}=6730 \mathrm{~L} \cdot \mathrm{mol}^{-1} \cdot \mathrm{cm}^{-1}$.

We irradiated this solution at increasing doses up to $3.6 \mathrm{kGy}$ and recorded the UV-vis absorption spectra as a function of the dose (results not shown). We reported in Figure 1 (inset), the absorption of Py at $205 \mathrm{~nm}$ as a function of the dose. One can observe the decrease of the absorption as a function of the irradiation dose, which means that Py is progressively consumed (according to a pseudo-first order exponential decay).

The initial radiolytic yield of Py consumption, G-Py0, corresponds to the value of the initial slope of the curve which can be deduced thanks to an exponential fit of the experiment curve:

$\mathrm{G}_{-\mathrm{Py} 0}\left(\mathrm{~mol} \cdot \mathrm{J}^{-1}\right)=-\left(\frac{\mathrm{d}[\mathrm{Py}]\left(\mathrm{mol} \cdot \mathrm{L}^{-1}\right)}{\mathrm{d} \mathrm{D}(\mathrm{Gy})}\right)_{0}=6.0 \times 10^{-7} \mathrm{~mol} \cdot \mathrm{J}^{-1}$

We clearly find that: $\mathrm{G}_{-\mathrm{Py} 0} \approx \mathrm{G}(\mathrm{HO} \bullet)$. This indicates that a concentration of $1 \mathrm{mM}$ in $\mathrm{Py}$ is sufficient to scavenge all the $\mathrm{HO}$ - radicals produced by radiolysis and demonstrates that only $\mathrm{HO} \cdot$ radicals react with $\mathrm{Py}$ monomers. Indeed, $\mathrm{HO} \cdot$ is a strong oxidizing species since its standard redox potential in neutral medium $(\mathrm{pH}=7)$ amounts to $\mathrm{E}^{0^{\prime}}{ }_{\mathrm{HSE}}\left(\mathrm{HO} \cdot / \mathrm{H}_{2} \mathrm{O}\right)=2.31 \mathrm{~V}_{\mathrm{HSE}}$ enabling oxidation of Py $\left(\mathrm{E}^{0^{\prime}}{ }_{\mathrm{HSE}}\left(\mathrm{Py}^{+} / \mathrm{Py}\right)=0.76 \mathrm{~V}_{\mathrm{ENH}}\right){ }^{34,35}$ Therefore, it is clear that, in our experimental conditions, the radiation induced polymerization of pyrrole can only be initiated by 
HO• as expected. Therefore, as previously explained, the dose needed for quantitative polymerization of Py could be easily calculated according to formula (5). In particular, $72 \mathrm{kGy}$ are needed for $20 \mathrm{mM}$ in Py.

\subsection{Highlighting $\gamma$-PPy radioinduced synthesis, a comparison with chemical synthesis}

\subsubsection{Identification of $\gamma$-PPy by spectroscopic studies}

While relatively low concentrations in Py monomers ( $1 \mathrm{mM}$, see previous section) were needed for the follow-up of their oxidation mechanism by UV-vis absorption spectroscopy, higher concentrations in Py were used for the characterization of PPy polymers.

Aqueous solutions containing $20 \mathrm{mM}$ in Py were irradiated at doses up to $72 \mathrm{kGy}$ (Figure 2). We can note that after a $72 \mathrm{kGy}$ - irradiation (spectrum b), only a shoulder is observable at $205 \mathrm{~nm}$ indicating that polymerization is indeed almost quantitative at $72 \mathrm{kGy}$ since only a small amount of Py monomers remains in solution. Py disappearance parallels the formation of species which absorb at $300 \mathrm{~nm}$ as observed in spectrum b. According to literature, ${ }^{36}$ the shoulder at $300 \mathrm{~nm}$ should be attributed to terpyrrole. Also, after a $72 \mathrm{kGy}$-irradiation, continuous scattering (long absorption tail) in the range 400 1000 $\mathrm{nm}$ whose intensity increases with irradiation dose, is observed in the extinction spectrum b. This is characteristic of the $\pi-\pi^{*}$ transition of PPy

materials with higher molecular weight. ${ }^{36-38}$ This scattering should result from the presence of a black suspension in the medium as observed in Figure 3 (image b). This suspension becomes denser and the solution appears more turbid as the irradiation dose increases. As it will be demonstrated later, this suspension corresponds to PPy polymers formed at high doses thanks to the $\mathrm{HO}^{\bullet}$-induced oxidation process. These polymers formed by radiolysis are called $\gamma$-PPy. Note that this suspension remains relatively stable and that no sedimentation process is observed in this case over few days. This may be explained by a relatively low molecular weight of the polymers. In addition, the absence of any deposition implies that $\gamma$-PPy polymers are not hydrophobic.

In order to compare our radiolytic procedure with a more common chemical methodology, we added $40 \mathrm{mM}$ of $\mathrm{K}_{2} \mathrm{~S}_{2} \mathrm{O}_{8}$ as oxidant to a solution containing $20 \mathrm{mM}$ in Py (ratio Py/ $\mathrm{K}_{2} \mathrm{~S}_{2} \mathrm{O}_{8}=$ 1:2) under stirring. After 24 hours, we recorded the absorption spectrum of the solution (Figure 2, spectrum c). This spectrum is somewhat different from the spectrum b. Indeed, one can note the 
presence of residual Py monomers characterized by the absorption at $205 \mathrm{~nm}$ meaning that, in our experimental conditions, chemical polymerization is less complete than radiation induced one. While no peak at $300 \mathrm{~nm}$, characteristic of terpyrrole, is observed in spectrum c of Figure 2, a continuous absorption in the range 400 1000 $\mathrm{nm}$ is present such as in the case of radiolytical method. This is once again characteristic of PPy materials with higher molecular weight. Nevertheless, the lower intensity of the extinction spectrum $\mathrm{c}$ in comparison with that of spectrum b could be explained by the sedimentation process which was systematically observed in the case of chemical method. Indeed, contrarily to radiolytical method, a black powder deposits in this latter case at the bottom of the solution as observed in Figure 3 (image c).

Thus, as in the case of radiolysis, PPy polymers are formed in aqueous solution thanks to chemical oxidation of Py. These polymers are called $\chi$-PPy. Nevertheless, these chemically synthesized polymers ( $\chi$-PPy) should be more hydrophobic than radiosynthesized ones $(\gamma$-PPy) or could have higher molecular weight since they precipitate.

In order to perform ATR-FTIR experiments for comparing the chemical nature of both $\gamma$-PPy and $\chi$-PPy, the two samples (images b and c of Figure 3) were lyophilized. In both cases, black powder was obtained (images $\mathrm{d}$ and e of Figure 3). Note that the solid volume obtained after lyophilization of $\gamma$-PPy is higher when the suspension is denser and when the irradiation dose increases. While the powder obtained after irradiation is only polymers, the powder obtained after chemical oxidation should also contain $\mathrm{K}_{2} \mathrm{~S}_{2} \mathrm{O}_{8}$ and its conjugated reducing species. This prevents any comparison between the chemical and radiolytical polymerization yields. On another hand, we attempted to estimate the molecular weights of $\gamma$-PPy and $\chi$-PPy polymers by Size-Exclusion Chromatography (SEC). However, the solubility of our polymers was too low in the different solvents usually used in SEC chromatography (ethanol, acetone, acetonitrile, THF...).

The ATR-FTIR spectrum of $\gamma$-PPy is presented in Figure 4 (spectrum b) in the wavenumber region 600 4000 $\mathrm{cm}^{-1}$ together with those of $\chi$-PPy (spectrum c) and pure non irradiated Py liquid sample (spectrum a). Note that the deposition of Py liquid phase is translated by a better resolution when compared with the solid phase deposition of polymer films.

The three obtained spectra are in good agreement with those previously reported for Py and PPy in literature. ${ }^{36,39,40}$ In addition, no significant difference exists between spectra b and c. Only small shifts in the vibration mode can be observed. Starting from what is known in literature about Py, vibration at $3396 \mathrm{~cm}^{-1}$ observed in spectrum a can be attributed to the in plane 
stretching of N-H. ${ }^{38,41}$ The bands at 1571 and $1467 \mathrm{~cm}^{-1}$ are due to $\mathrm{C}-\mathrm{C}$ in-ring-stretch mode and stretching vibration of pyrrole rings respectively. ${ }^{29,39}$ The band at $1047 \mathrm{~cm}^{-1}$ is mostly attributed to $\mathrm{C}-\mathrm{C}$ out-of-plane deformation vibration. ${ }^{39,41}$ The strong band at $726 \mathrm{~cm}^{-1}$ results from the $\mathrm{C}-\mathrm{H}$ wag vibration at $\alpha, \alpha^{\prime}$ positions. ${ }^{40}$ After polymerization, the $\mathrm{C}-\mathrm{H}$ wag vibration and $\mathrm{N}-\mathrm{H}$ in plane stretching, observed in spectra $\mathrm{b}$ and $\mathrm{c}$, decrease obviously indicating that free pyrrole monomers are not observable here, suggesting that polymerization of pyrrole is relatively quantitative.

In the case of chemically synthesized PPy (Figure 4, spectrum c), the broad band at $3120 \mathrm{~cm}^{-1}$ corresponds to the stretch of N-H bond and the peak at $1700 \mathrm{~cm}^{-1}$ corresponds to the stretch of $\mathrm{C}=\mathrm{O} .{ }^{42}$ The presence of this latter bond seems surprising. Nevertheless, $\mathrm{C}=\mathrm{O}$ bond has already been observed in literature in the case of chemical polymerization of Py and assigned to the overoxidation of polypyrrole. ${ }^{36}$ The bands at 1556, 1481 and $1043 \mathrm{~cm}^{-1}$ correspond to stretching mode of $\mathrm{C}=\mathrm{C}, \mathrm{C}-\mathrm{N}$ and $\mathrm{C}-\mathrm{C}$ out-of-plane vibration indicating the formation of PPy. ${ }^{39}$ The bands at 1184 and $916 \mathrm{~cm}^{-1}$ are attributed to the $\mathrm{S}=\mathrm{O}$ group and stretching vibration of PPy showing that chemically synthesized PPy is doped with the oxidant. ${ }^{29,41}$

In the case of PPy synthesized by radiolytical method (Figure 4, spectrum b), some bands are more or less displaced. The bands at 1180, 1099 and 1045 correspond to $\mathrm{C}-\mathrm{H},=\mathrm{C}-\mathrm{H}$ in-plane and C-C out-of plane vibration proving the successful preparation of PPy. ${ }^{36,39,41}$ Nevertheless, there is an obvious carbonyl $\mathrm{C}=\mathrm{O}$ group peak at $1674 \mathrm{~cm}^{-1}$ which is more intense than the $\mathrm{C}=\mathrm{O}$ peak observed at $1700 \mathrm{~cm}^{-1}$ in the case of $\chi$-PPy. The presence of this peak obviously demonstrates that $\gamma$-PPy is overoxidized. ${ }^{36,43}$ The spectrum of $\gamma$-PPy also exhibits a very large band around 3251 $\mathrm{cm}^{-1}$. As in the case of $\chi$-PPy (spectrum c), this band is attributed to the $\mathrm{N}-\mathrm{H}$ bond. The observation of such a very large band should result from the N-H groups of the polymers. On the other hand, this very large and relatively intense band observed in the case of $\gamma$-PPy could also come from the $-\mathrm{OH}$ functionalization of the polymers by $\mathrm{HO} \cdot$ radicals. This has already been established in the case of radiation induced synthesis of PEDOT and is in very good agreement with literature since $\mathrm{HO}$ - radicals are known to add to the double bonds of organic molecules. ${ }^{39}$, 44,45

Therefore, PPy was successfully synthesized by both radiolytical and chemical methods. Nevertheless, radiosynthesized PPy polymers could be functionalized by both $\mathrm{O}-\mathrm{H}$ and $\mathrm{C}=\mathrm{O}$ groups which should then explain their higher hydrophilicity in comparison with that of $\chi$-PPy. 


\subsubsection{Morphological observations of $\gamma$-PPy}

As the solubility in water of PPy synthesized by radiolytic method ( $\gamma$-PPy) is relatively high, the in-situ observation of the morphology of $\gamma$-PPy is possible by Cryo-TEM. Aqueous solutions containing $20 \mathrm{mM}$ in Py and irradiated at $72 \mathrm{kGy}$ were observed by cryo-transmission electron microscopy just after irradiation. Representative images showed the presence of low density globular structures forming polydisperse spherical nanoparticles the diameter of which was comprised between 80 and $200 \mathrm{~nm}$ as observed on Figure 5a (mean diameter of $100 \mathrm{~nm}$ ). Also, these particles systematically appeared self-assembled into nanochaplets as observed in Figure $5 \mathrm{~b}$. These results are in good agreement with previous observations reported in literature concerning such polymer systems. ${ }^{46,47}$

Since no other low density objects were observed during Cryo-TEM experiments, we deduce that these more or less spherical nanoparticles are made up of radiosynthesized PPy polymers. Each globular structure observed on Figure 5 should correspond to the self-assembly of independent amorphous PPy polymer chains which interact all together by Hydrogen-bonds as already reported in literature. ${ }^{45,48}$ Also, the packing of the polymers into supramolecular nanochaplets should also result from such intermolecular interactions.

In order to definitely prove the PPy nature of these spherical nanoparticles, in order to characterize the morphology of the polymers after a deposition procedure and also to check whether a drying process is able to affect the morphology of PPy, a drop of the solution containing the PPy black suspension obtained after a $72 \mathrm{kGy}$-irradiation (polymers of Figure 5) was deposited onto a ZnSe prism, then dried naturally at air, and finally imaged and characterized by AFM-IR as shown in Figure 6. According to the AFM image of $\gamma$-PPy recorded in contact mode (Figure 6a), the top dark areas having no thickness correspond to the substrate. The topography of $\gamma$-PPy displayed as the bright areas correspond to the thicker regions made up of isolated bigger spherical PPy nanoparticles and closely packed smaller ones (200 300 nm in average). ${ }^{49}$ This AFM observation agrees well with the morphology of $\gamma$-PPy particles previously observed in aqueous solution by Cryo-TEM (Figure 5) without any significant change in the mean size and in the shape. Then, the packing of the particles and their flattening onto the substrate when deposited and dried do not seem to affect the morphology of $\gamma$-PPy polymers.

In order to confirm that the nanoparticles observed by Cryo-TEM (Figure 5) and by AFM in 
contact mode (Figure 6a) are made-up of PPy polymers, the sample was observed by AFM-IR in the range of 1600 1800 $\mathrm{cm}^{-1}$ (Figure 6b). The spectrum of Figure $6 \mathrm{~b}$ displays a peak at $1674 \mathrm{~cm}^{-1}$ which is characteristic of $\mathrm{C}=\mathrm{O}$ bonds. Now, these bonds have been detected by ATR-FTIR spectroscopy in $\gamma$-PPy polymers (Figure 4, spectrum b) and not in Py monomers (Figure 4, spectrum a). This demonstrates that the globular structures observed in both Figure 5 and Figure 6a contain close-packed PPy polymers.

Since the AFM-IR technique also enables the chemical mapping of the sample, this wavenumber $1674 \mathrm{~cm}^{-1}$ was chosen for AFM-IR chemical mapping of our sample (Figure 6c). In Figure $6 \mathrm{c}$, the red and yellow areas indicate a stronger absorption at the characteristic wavenumber which is caused by a thick layer of $\gamma$-PPy $(\sim 500 \mathrm{~nm})$ linked onto the prism. Compared with the topography of the sample (Figure 6a), we notice that these thick areas correspond to the bright regions of the $\gamma$-PPy. As the distribution of $\gamma$-PPy nanoparticles on the prism is inhomogeneous, the appearance of AFM-IR is not totally the same as its topography. Nevertheless, the signal of AFM-IR (Figure 6c) fits well with the thickness of $\gamma$-PPy (Figure 6a). Thus, we can definitely assume that the nanoparticles observed on Figure 6 are essentially composed of $\gamma$-PPy polymers. Nevertheless, the presence of some residual Py monomers trapped into PPy nanoparticles couldn't be totally excluded.

This result does not only prove that radiosynthesized PPy are spherical nanoparticles but also further explains their hydrophilicity and their packing into nanochaplets. Indeed, the presence of $\mathrm{C}=\mathrm{O}$ bonds at the surface of the PPy nanoparticles, as demonstrated by AFM-IR, should enhance the probable effect of $\mathrm{O}-\mathrm{H}$ functionalities, leading to strong hydrogen-bonds interactions between the self-assembled nanoparticles as well as with the aqueous solvent.

In order to check whether the lyophilization procedure and whether the substrate nature affect the morphology of $\gamma$-PPy nanoparticles, the lyophilized PPy powder obtained after a 72 kGy-irradiation was observed by SEM microscopy. Typical image is displayed on Figure 7a. Once again, $\gamma$-PPy polymers appear as more or less spherical nanoparticles with a mean size of $100 \mathrm{~nm}$. This definitely proves that the presence of the solvent, that the lyophilization, that the nature of the substrate have no influence on the morphology of the polymers. This would imply the existence of very strong hydrogen-bond interactions into each nanoparticle.

In order to compare the morphology of $\gamma$-PPy with that of $\chi$-PPy, the lyophilized PPy powder obtained in the presence of $40 \mathrm{mM}$ in $\mathrm{K}_{2} \mathrm{~S}_{2} \mathrm{O}_{8}$ was also observed by SEM (Figure $7 \mathrm{~b}$ ). $\chi$-PPy 
polymers also appear as more or less close-packed spherical nanoparticles. ${ }^{50}$ However, the value of the mean-size $(\sim 200 \mathrm{~nm})$ and that of the polydispersity are much higher than those corresponding to $\gamma$-PPy. This result proves that our radiolytic methodology does not only lead to more hydrophilic PPy polymers, but also to smaller and less polydisperse PPy nanoparticles. The lower hydrophilicity and the bigger size of $\chi$-PPy nanoparticles in comparison with those of $\gamma$ PPy structures could explain their sedimentation observed just after their chemical synthesis into water (Figure 3, image c).

\subsection{Physico-chemical properties of $\gamma$-PPy, a comparison with $\chi$-PPy}

\subsubsection{Thermal stability}

We wanted to check and to compare the thermal stability of $\gamma$-PPy and $\chi$-PPy previously synthesized and obtained as powders after lyophilization. The thermo gravimetric analysis (TGA) plots of both PPy polymers are shown in Figure 8. The inset displays the temperature at which the weight loss of PPy occurs. In the case of $\gamma$-PPy (Figure 8a), the weight loss exhibits three stages of decomposition which is in agreement with literature. ${ }^{51}$ From 40 to $100{ }^{0} \mathrm{C}$, the main loss of weight happens at $50{ }^{0} \mathrm{C}$ which may be caused by the loss of some unreacted pyrrole. Then, in the range $100-400{ }^{0} \mathrm{C}$, the weight loss at $176{ }^{\circ} \mathrm{C}$ may be caused by the loss of terpyrrole which was observed by UV-visible absorption spectroscopy (Figure 2, spectrum b), while the main weight loss which occurs at about $330{ }^{0} \mathrm{C}$ may correspond to the decomposition of some $\gamma$-PPy oligomers characterized by relatively low molecular weights. ${ }^{36}$ Finally, the decomposition of the backbone of PPy occurs around $600{ }^{0} \mathrm{C}$. This TGA analysis is in very good agreement with TGA data already reported in literature concerning PPy polymers. ${ }^{41,52}$ Note that the same thermal stability is found for $\chi$-PPy as observed on Figure $8 \mathrm{~b}$. This result indicates that the size of the PPy polymer nanoparticles as well as their functionalization by $\mathrm{C}=\mathrm{O}$ or $\mathrm{O}-\mathrm{H}$ groups seem to have no effect on their thermal behavior.

\subsubsection{Electrical conductivity}

We wanted to check and to compare the electrical conductivity of $\gamma$-PPy and $\chi$-PPy by four 
point probe technique. In this aim, we doped both samples with $\mathrm{NOBF}_{4}(10 \mathrm{mM})$. We found that the electrical conductivity of $\chi$-PPy is $1.2 \times 10^{-2} \mathrm{~S} \cdot \mathrm{cm}^{-1}$. This value is similar to those reported in literature. $^{53}$ Nevertheless, the electrical conductivity of $\gamma$-PPy synthesized by our original radiolytical procedure was found to be higher: $5.7 \times 10^{-2} \mathrm{~S} \cdot \mathrm{cm}^{-1}$. This result proves that, even if the thermal stability of $\gamma$-PPy is not better than that of $\chi$-PPy, the value of the electrical conductivity of $\gamma$-PPy is nearly five times higher than that of $\chi$-PPy. The higher conductivity of $\gamma$-PPy could be related to the smaller particles size and the bigger surface areas. ${ }^{54,55}$ Indeed, as the diameter decreases, more ordered chains of connected structure of $\gamma$-PPy networks could counteract the influence of insulated cavities and bigger surface areas could enhance the delocalisation of charge carriers over an extended region of the polymer chains. We think that both aspects contribute to a relatively higher electrical conductivity of $\gamma$-PPy.

\section{Conclusion}

We recently succeeded in the development of a new $\gamma$-radiolysis-based alternative way for synthesizing PEDOT polymers in solution. In the present paper, we extended this methodology as an alternative green way for the synthesis of conducting PPy polymers in aqueous solution.

PPy polymers synthesized by radiolysis are characterized by a very good long-term stability at air in a humid environment. We showed that the as-prepared PPy polymers remain welldispersed in water, can be easily dried and are quite simply redispersed in protic solvents. As revealed by ATR-FTIR spectroscopy, the probable presence along the polymeric chains of $\mathrm{O}-\mathrm{H}$ and $\mathrm{C}=\mathrm{O}$ functionalities, which should come from the addition of hydroxyl radicals during the polymer growth, could explain the hydrophilic properties of the radiosynthesized PPy polymers. This could also justify the existence in aqueous solution of the globular self-assembled structures made up of PPy polymeric chains and their packing into nanochaplets as observed by cryo-TEM.

After deposition onto substrate, the radiosynthesized PPy polymers appear as more or less spherical nanoparticles as revealed by AFM and SEM observations. Moreover, in an original way, high resolution atomic force microscopy, coupled with infrared nanospectroscopy was used to probe the local chemical composition of PPy nanostructures.

A detailed investigation enabled the comparison between the properties of radiosynthesized 
PPy and those of PPy synthesized by a conventional chemical polymerization. We found that radiosynthesized PPy nanoparticles are more hydrophilic, smaller and less polydisperse than chemically synthesized PPy. Besides, we demonstrated that radiosynthesized PPy nanostructures are characterized by a very good thermal stability and an electrical conductivity which is five times higher than that of chemically synthesized PPy.

Work is in due course in order to enhance the conductivity of radiosynthesized PPy polymers by the way of the improvement of their doping level and thanks to the increase in their conjugation length. Also, in order to control the growth and the morphology of the radiosynthesized PPy polymers, soft templates such as hexagonal mesophases or spherical micelles will be used.

Finally, the study of the influence of polymerization mechanism remains poorly investigated in literature in the field of conducting materials. We thus aim to progress in this domain in order to find out the better way to optimize the preparation of nanostructured conducting polymers with adjusted morphologies and tuned properties. Pulsed radiolysis studies are underway in order to identify the first steps of the polymerization mechanism and in order to better understand the growth process of PPy polymers in aqueous solution.

\section{AUTHOR INFORMATION}

*Corresponding author. E-mail: samy.remita@u-psud.fr. Tel.: +33 (0)1 691544 41;

\section{ACKNOWLEDGEMENTS}

We acknowledge the financial support from the China Scholarship Council (CSC). We thank Fabrice Goubard and Pierre-Henri Aubert (LPPI, Université Cergy-Pontoise, France) for conductivity measurements. Also, we thank Jean-Michel Guigner (IMPMC, Université Pierre et Marie Curie, France) for Cryo-TEM experiments. 


\section{REFERENCES}

(1) Shirakawa, H. Angew. Chem. Int. Ed. 2001, 40, 2574-2580.

(2) Heeger, A. J. Angew. Chem. Int. Ed. 2001, 40, 2591-2611.

(3) MacDiarmid, A. G. Angew. Chem. Int. Ed. 2001, 40, 2581-2590.

(4) Heeger, A. J. Chem. Soc. Rev. 2010, 39, 2354-2371.

(5) Ohkita, H.; Ito, S. Polymer 2011, 52, 4397-4417.

(6) Wanekaya, A. K.; Bangar, M. A.; Yun, M.; Chen, W.; Myung, N. V.; Mulchandani, A. J. Phys. Chem. C 2007, 111, 5218-5221.

(7) Forzani, S. E.; Zhang, H. Q.; Nagahara, L. A.; Amlani, I.; Tsui, R.; Tao, N. J. Nano Lett. 2004, 4, 1785-1788.

(8) Kannan, B.; Williams, D. E.; Laslau, C.; Travas-Sejdic, J. Biosens. Bioelectron. 2012, 35, 258-264.

(9) Yao, B.; Wang, G. C.; Ye, J. K.; Li, X. W. Mater. Lett. 2008, 62, 1775-1778.

(10) Groenendaal, L.; Jonas, F.; Freitag, D.; Pielartzik, H.; Reynolds, J. R. Adv. Mater. 2000, 12, 481-494.

(11) De Jesus, M. C.; Fu, Y.; Weiss, R. A. Polym. Eng. Sci. 1997, 37, 1936-1943.

(12) Uter, W.; Stropp, G.; Schnuch, A.; Lessmann, H. Ann. Occup. Hyg. 2007, 51, 219-226.

(13) Harun, H. M.; Saion, E.; Kassim, A.; Yahya, N.; Mahmud, M. JASA 2007, 2, 63-68.

(14) Khulbe, K. C.; Mann, R. S.; Khulbe, C. P. J. Polym. Sci., Part A: Polym. Chem. 1982, 20, 1089-1095.

(15) Li, X.; Wan, M. X.; Wei, Y.; Shen, J. Y.; Chen, Z. J. J. Phys. Chem. B. 2006, 110, 14623-14626.

(16) Leonavicius, K.; Ramanaviciene, A.; Ramanavicius, A. Langmuir 2011, 27, 10970-10976.

(17) Li, C.; Bai, H.; Shi, G. Q. Chem. Soc. Rev. 2009, 38, 2397-2409.

(18) Ramanaviciene, A.; Kausaite-Minkstimiene, A.; Oztekin, Y.; Carac, G.; Voronovic, J.; German, N.; Ramanavicius, A. Microchimica Acta 2011, 175, 79-86.

(19) Barkade, S. S.; Pinjari, D. V.; Singh, A. K.; Gogate, P. R.; Naik, J. B.; Sonawane, S. H.; Ashokkumar, M.; Pandit, A. B. Ind. Eng. Chem. Res. 2013, 52, 7704-7712.

(20) Nam, D. H.; Kim, M. J.; Lim, S. J.; Song, I. S.; Kwon, H. S. J. Mater. Chem. A 2013, 1, 8061-8068.

(21) Zhang, X. T.; Zhang, J.; Song, W. H.; Liu, Z. F. J. Phys. Chem. B 2006, 110, 1158-1165.

(22) Wang, D.; Li, Y. X.; Shi, Z.; Qin, H. L.; Wang, L.; Pei, X. F.; Jin, J. Langmuir 2010, 15, 8259-8264.

(23) Varmenot, N.; Remita, S.; Abedinzadeh, Z.; Wisniowski, P.; Strzelczak, G.; Bobrowski, K. J. Phys. Chem. A 2001, 105, 6867-6875.

(24) Lattach, Y.; Besseau, A. D.; Guigner, J. A.; Remita, S. Radiat. Phys. Chem. 2013, 82, 44-53.

(25) Lattach, Y.; Coletta, C.; Ghosh, S.; Remita, S. ChemPhysChem 2014, 15, 208-218.

(26) Spinks, J. W. T.; Woods, R. J. An introduction to radiation chemistry. John Wiley \& Sons, Inc. 1990, 3, 251-256.

(27) Ferradini, C.; Jay-Gerin, J. P. Res. Chem. Intermed. 2000, 6, 549-565.

(28) Ferradini, C.; Jay-Gerin, J. P. Can. J. Chem. 1999, 77, 1542-1575.

(29) Zhong, W. B.; Li, S. M.; Chen, X. H.; Wang, Y. X.; Yang, W. T. Macromolecules 2006, 39, 3224-3230.

(30) Dazzi, A.; Prazeres, R.; Glotin, F.; Ortega, J. M. Opt. Lett. 2005, 30, 2388-2390.

(31) Policar, C.; Waern, J. B.; Plamont, M. A.; Clede, S.; Mayet, C.; Prazeres, R.; Ortega, J. M.; Vessieres, A.; Dazzi, 
A. Angew. Chem., Int. Ed. 2011, 50, 860-864.

(32) Dazzi, A.; Prater, C. B.; Hu, Q. C.; Bruce Chase, D.; Rabolt, J. F.; Marcott, C. Appl. Spectrosc. 2012, 66, 13651384.

(33) Silverstein, R. M.; Bassler, G. C. Spectrometric identification of organic compounds. John Wiley \& Sons, Inc. 1998, 7, 311 .

(34) Koppenol, W. H.; Stanbury, D. M.; Bounds, P. L. Free Radical Biol. Med. 2010, 49, 317-322.

(35) Martínez, M. W.; Thompson, T. T.; Smit, M. A. Int. J. Electrochem. Sci. 2010, 5, 931-943.

(36) Vetter, C. A.; Suryawanshi, A.; Lamb, J. R.; Law, B.; Gelling, V. J. Langmuir 2011, 13719-13728.

(37) Ye, S. J.; Fang, L.; Lu, Y. Phys. Chem. Chem. Phys. 2009, 11, 2480-2484.

(38) Li, X. G.; Hou, Z. Z.; Huang, M. R.; Moloney, M. G. J. Phys. Chem. C 2009, 113, 21586-21595.

(39) Li, X. G.; Li, A.; Huang, M. R.; Liao, Y. Z.; Lu, Y. G. J. Phys. Chem. C 2010, 114, 19244-19255.

(40) Scienza, L. C.; Thompson, G. E. Polimeros 2001, 11, 142-148.

(41) Hazarika, J.; Kumar, A. Synth. Met. 2013, 175, 155-162.

(42) Hawkins, S. J.; Ratcliffe, N. M. J. Mater. Chem. 2000, 10, 2057-2062.

(43) Wang, H. L.; Fernandez, J. E. Macromolecules 1992, 25, 6179-6184.

(44) Choi, S.; Kim, K.; Nam, J.; Shim, S. E. Carbon 2013, 60, 254-265.

(45) Talarico, A. M.; Szerb, E. I.; Mastropietro, T. F.; Aiello, I.; Crispini, A.; Ghedini, M. Dalton Trans. 2012, 41, 4919-4926.

(46) Chatterjee, S.; Shit, A.; Nandi, A. K. J. Mater. Chem. A 2013, 1, 12302-12309.

(47) Jang, J.; Oh, J. H. Adv. Funct. Mater. 2005, 15, 494-502.

(48) Zang, J. F.; Bao, S. J.; Li, C. M.; Bian, H. J.; Cui, X. Q.; Bao, Q. L.; Sun, C. Q.; Guo, J.; Lian, K. R. J. Phys. Chem. C 2008, 112, 14843-14847.

(49) Vasilyeva, S. V.; Vorotyntsev, M. A.; Bezverkhyy, I.; Lesniewska, E.; Heintz, O.; Chassagnon, R. J. Phys. Chem. C 2008, 112, 19878-19885.

(50) Xu, P.; Han, X. J.; Wang, C.; Zhou, D. H.; Lv, Z. S.; Wen, A. H.; Wang, X. H.; Zhang, B. J. Phys. Chem. B 2008, $112,10443-10448$.

(51) Guo, J.; Gu, H. B.; Wei, H. G.; Zhang, Q. Y.; Haldolaarachchige, N.; Li, Y.; Young, D. P.; Wei, S. Y.; Guo, Z. H. J. Phys. Chem. C 2013, 117, 10191-10202.

(52) Yang, C.; Liu, P. Synth. Met. 2010, 160, 768-773.

(53) Shen, C.; Sun, Y.; Yao, W.; Lu, Y. Polymer 2014, 55, 2817-2824.

(54) Ghosh, S.; Remita, H.; Ramos, L.; Dazzi, A.; Deniset-Besseau, A.; Beaunier, P.; Goubard, F.; Aubert, P. H.;

Brisset, F.; Remita, S. New J. Chem. 2014, 38, 1106-1115.

(55) Peng, S. J.; Tian, L. L.; Liang, J.; Mhaisalkar, S. G.; Ramakrishna, S. ACS Appl. Mat. Interfaces 2012, 4, $397-$ 404. 


\section{Scheme 1}
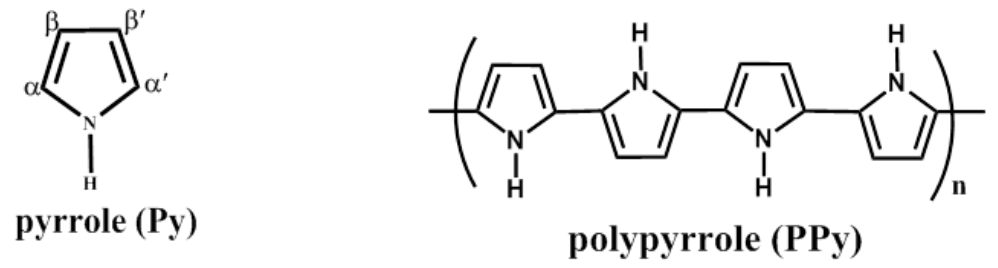

Scheme 1. Chemical structures of pyrrole (Py) and polypyrrole (PPy). The free $\alpha, \alpha^{\prime}$ positions at which polymerization occurs are shown in the pyrrole structure. 


\section{Figure 1}

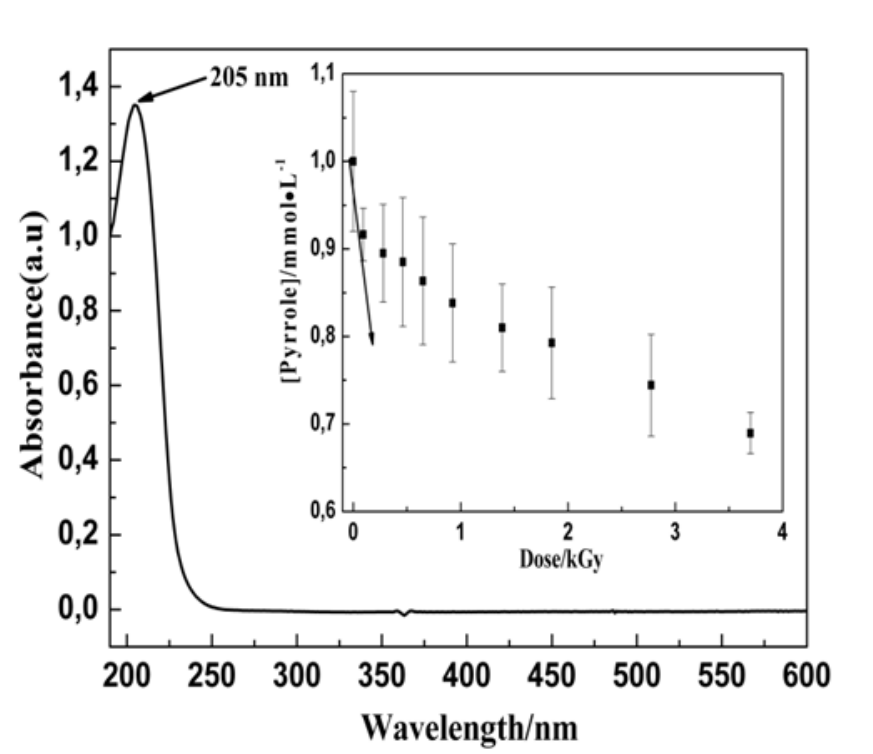

Figure 1. UV-vis absorption spectrum of aqueous solution of pyrrole (1 mM). Insert: evolution of pyrrole concentration as a function of the irradiation dose, $\mathrm{L}=0.2 \mathrm{~cm}$, Reference: water. 


\section{Figure 2}

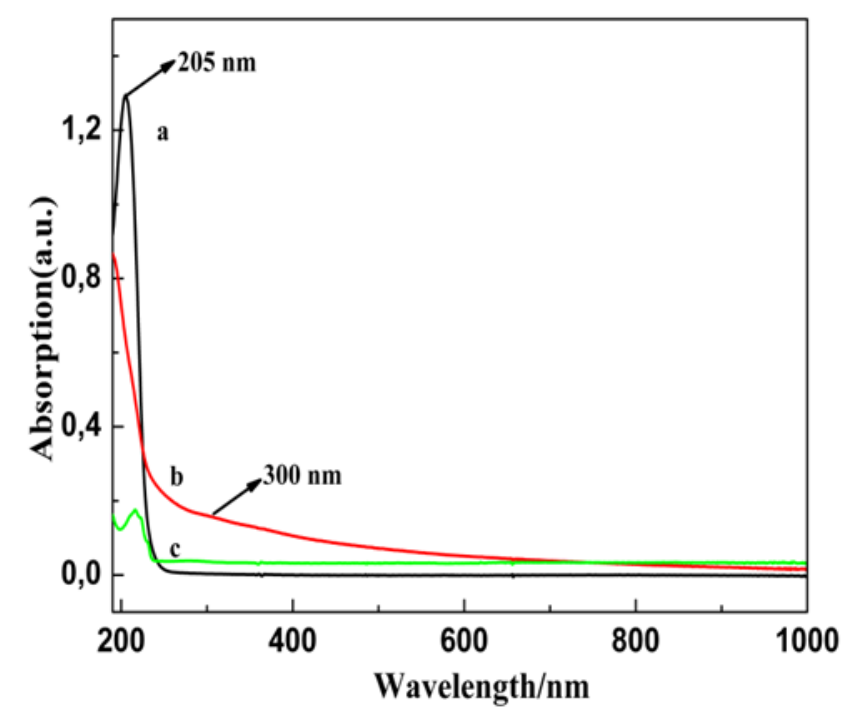

Figure 2. UV-vis absorption spectra of pyrrole before and after polymerization by radiolytic and chemical methods. (a) Aqueous solution of pyrrole $(20 \mathrm{mM})$ before polymerization (diluted 20 times), (b) PPy synthesized by radiolytic method, $\gamma$-PPy (diluted 20 times), and (c) PPy synthesized by chemical method, $\chi$-PPy (diluted 20 times), L= $0.2 \mathrm{~cm}$, Reference: water. 


\section{Figure 3}

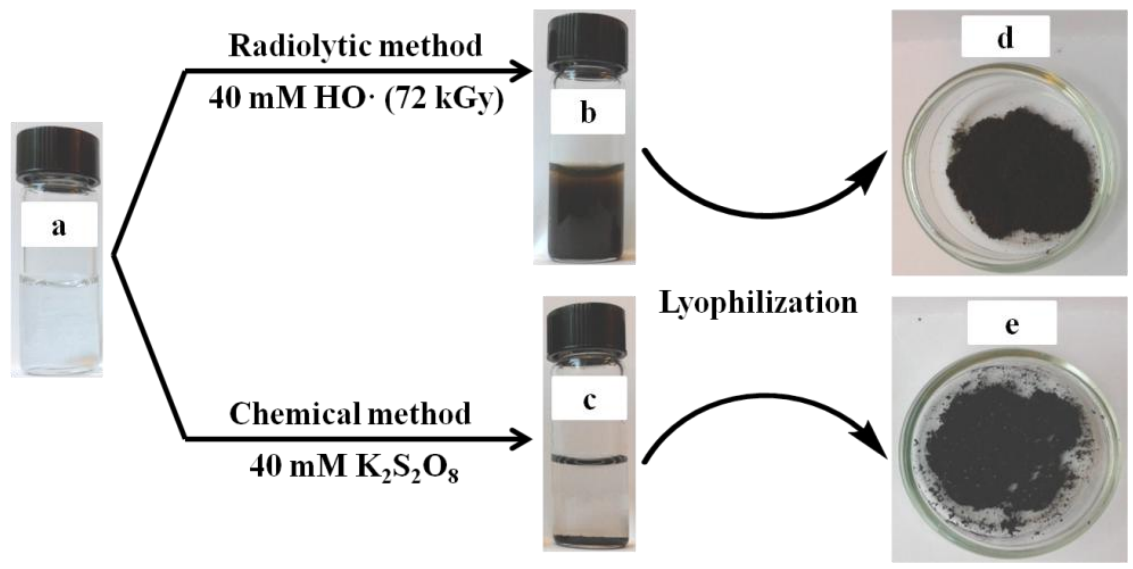

Figure 3. Photographs of Py samples before (a), after polymerization (b) and (c) and after lyophilization (d) and (e). 


\section{Figure 4}

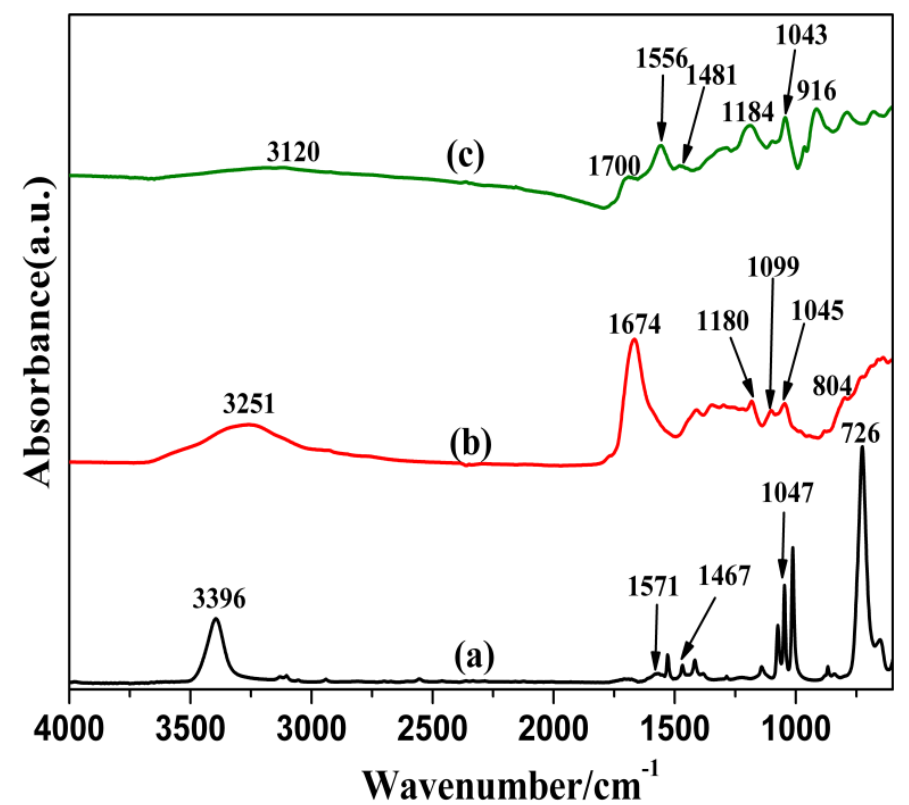

Figure 4. ATR-FTIR spectra of pure pyrrole before polymerization (a), radiosynthesized PPy after lyophilization (b), and chemically synthesized PPy after lyophilization (c). 


\section{Figure 5}

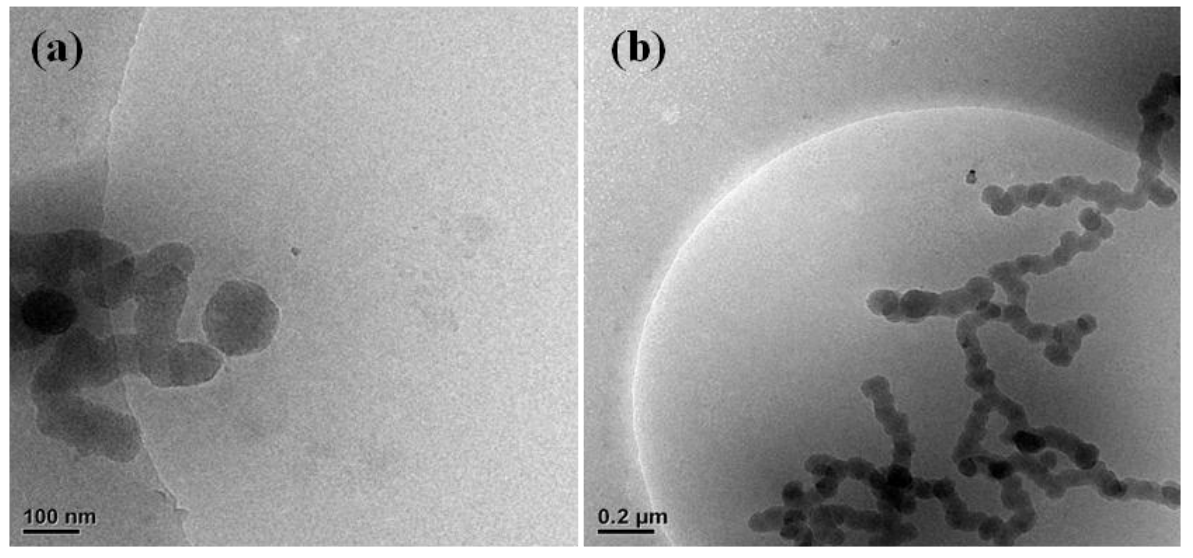

Figure 5. Cryo-TEM images of radiosynthesized PPy ( $\gamma$-PPy) at $72 \mathrm{kGy}$. (a) Nanostructures of $\gamma$ PPy, (b) full view of chaplets of $\gamma$-PPy. 


\section{Figure 6}

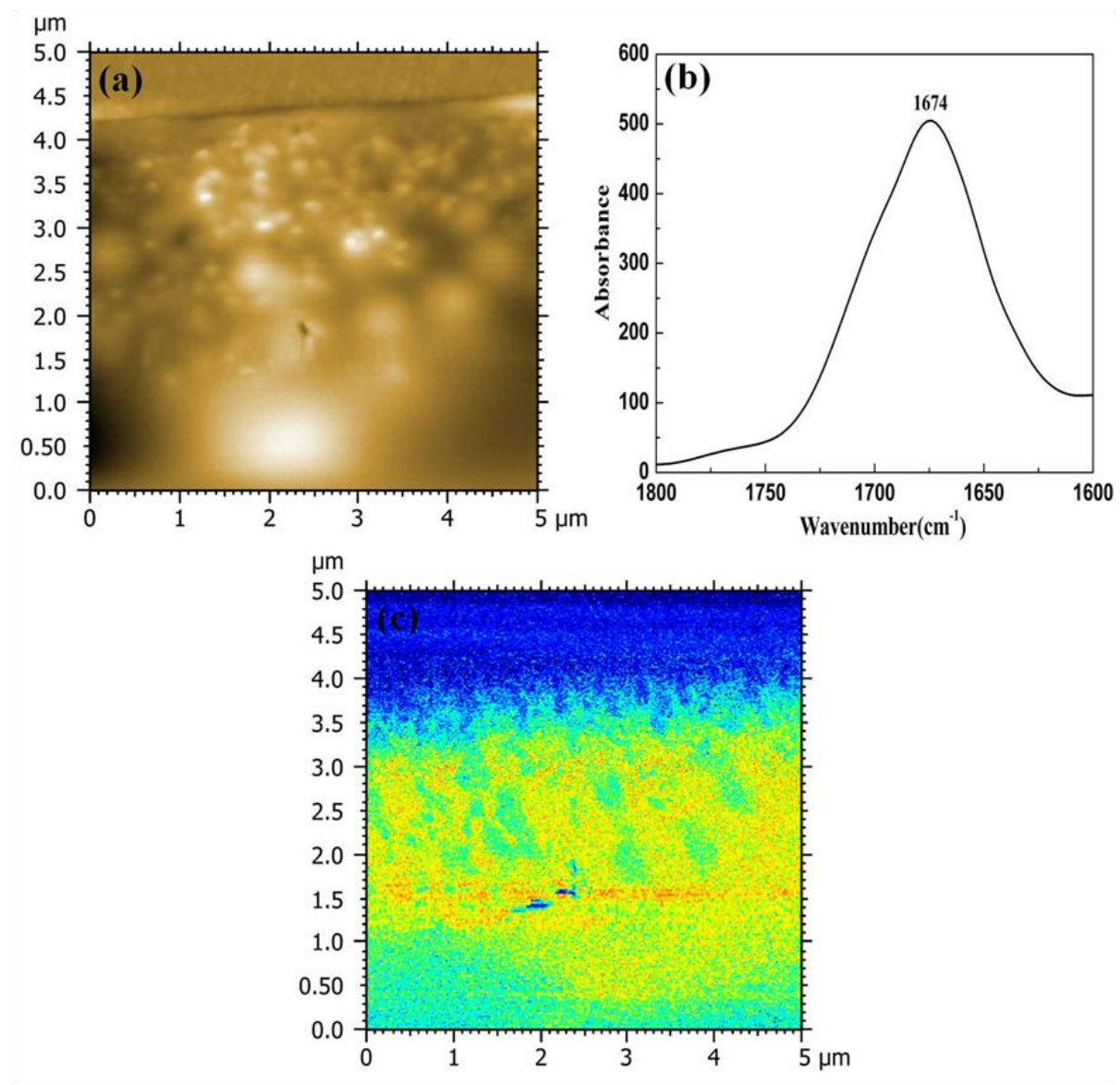

Figure 6. (a) AFM topographic image of $\gamma$-PPy in contact mode, (b) AFM-IR spectrum of PPy, and (c) AFM-IR chemical mapping of PPy with the IR source tuned to the $\mathrm{C}=\mathrm{O}$ band at $1674 \mathrm{~cm}^{-1}$. 


\section{Figure 7}

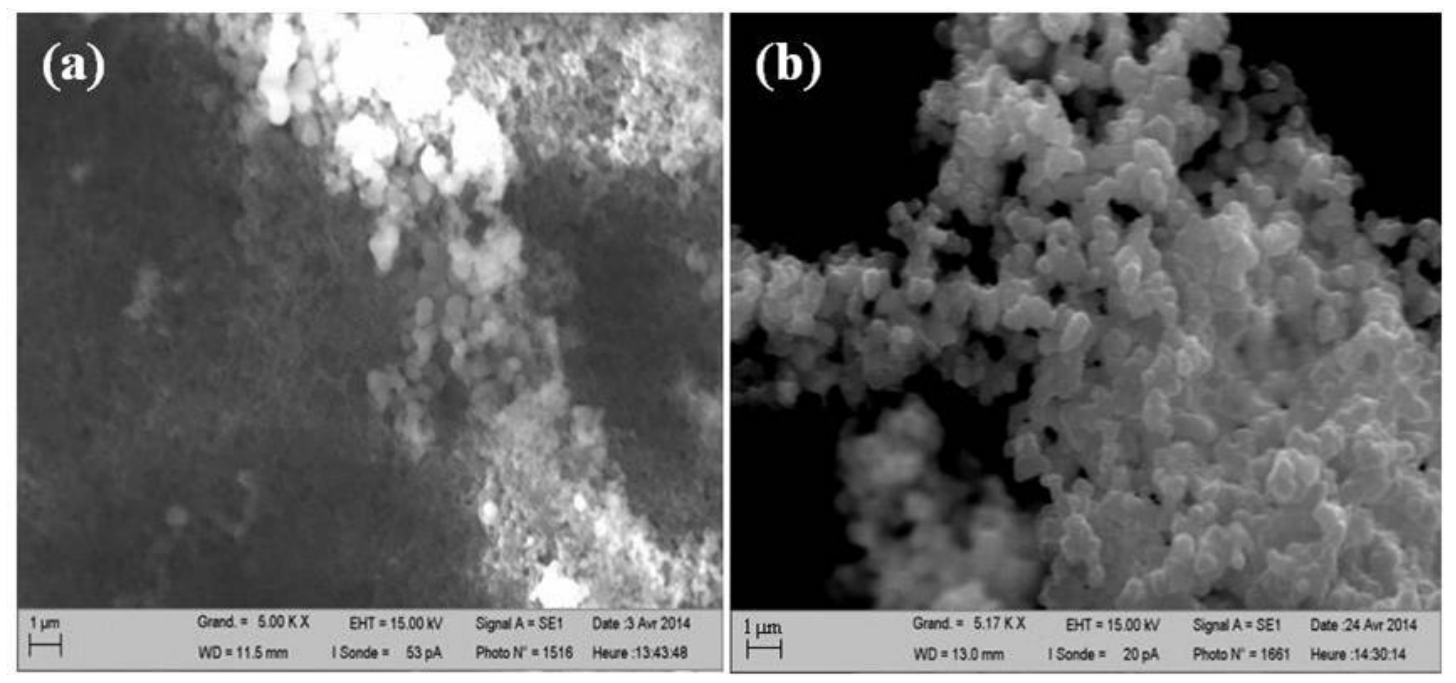

Figure 7. SEM images of PPy lyophilized after radiolytical (a) or chemical (b) synthesis. 


\section{Figure 8}
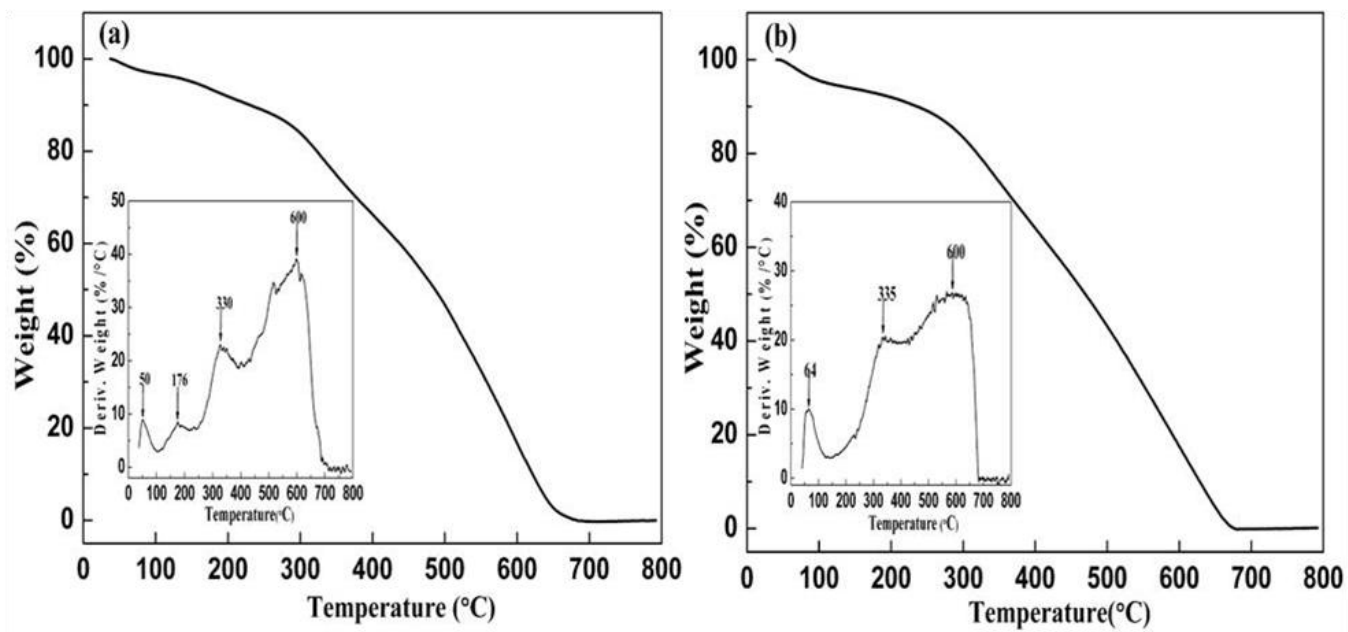

Figure 8. Thermo gravimetric analysis (TGA) plots of PPy synthesized by radiolytic method (a) or chemical method (b). Insert: the weight derivative curves of PPy as the temperature changes. 


\section{Table of Contents Graphic}

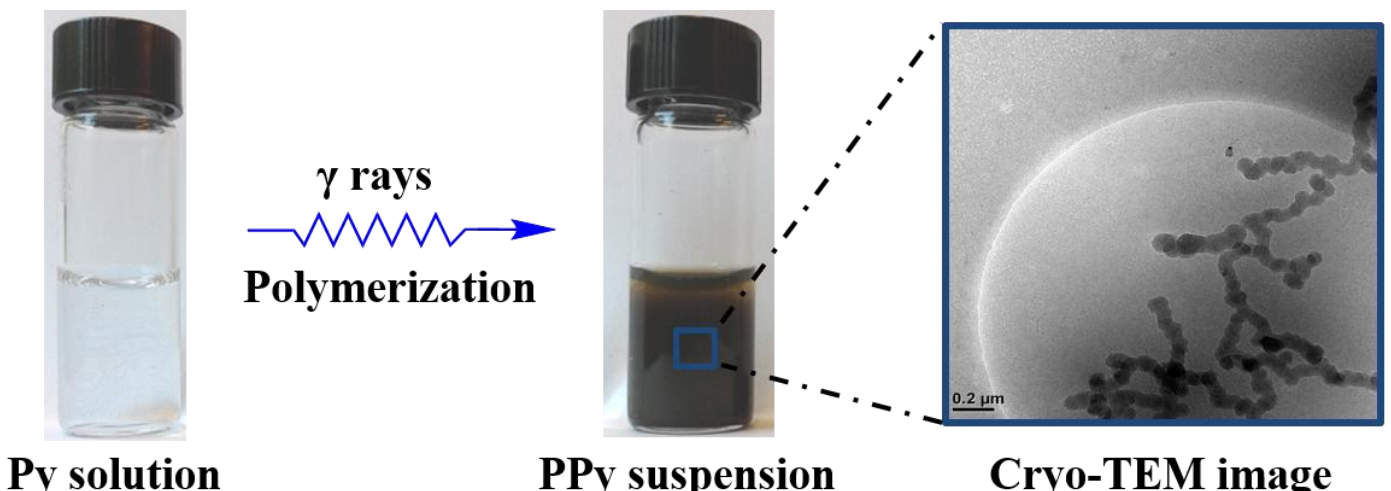

Py solution

PPy suspension

Cryo-TEM image

$\prod_{\substack{\mathrm{N} \\ \mathbf{H}}}^{1}$

pyrrole

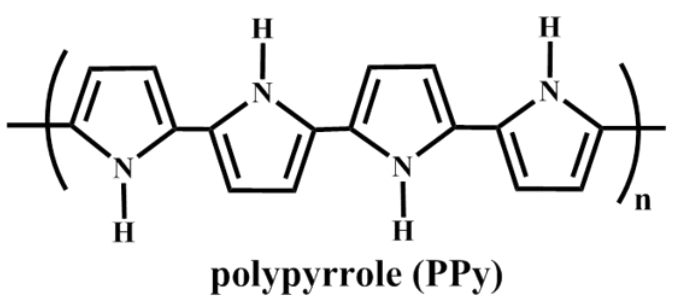

